\title{
The Two Triangles: What Did Wicksell and Keynes Know about Macroeconomics that Modern Economists do not (consider)?*
}

\author{
Roberto Tamborini \\ University of Trento \\ roberto.tamborini@economia.unitn.it \\ Hans-Michael Trautwein \\ University of Oldenburg \\ michael.trautwein@uni-oldenburg.de \\ Ronny Mazzocchi \\ University of Siena \\ ronny.mazzocchi@unisi.it
}

This version: September 2009

\begin{abstract}
The current consensus in macroeconomics, as represented by the New Neoclassical Synthesis, is to work within frameworks that combine intertemporal optimization, imperfect competition and sticky prices. We contrast this NNS triangle with a model in the spirit of Wicksell and Keynes that sets the focus on interest-rate misalignments as problems of intertemporal coordination of consumption and production plans in imperfect capital markets. We show that, with minimal deviations from the standard perfect competition model, a model structure can be derived that looks similar to the NNS triangle, but yields substantially different conclusions with regard to the dynamics of inflation and output gaps and to the design of the appropriate rule for monetary policy.
\end{abstract}

JEL classification: E20, E31, E32, E52, D84

${ }^{*}$ We wish to thank Robert M. Solow, Peter Spahn and the CNRS at Université de Nice - Sophia Antipolis for helpful comments and discussions. 


\section{Introduction}

If anyone is to blame for the awkwardness of the title of this paper, it should be Olivier Blanchard. Looking back on the 20th Century, Blanchard (2000) raised the question: "What do we know about macroeconomics that Wicksell and Fisher did not?" His answer was: "... a lot", stressing that much progress has been made in modelling short-run fluctuations of aggregate output as effects of "imperfections", i.e. as results of "deviations from the standard perfect competition model" ${ }^{1}$. In another prominent review, Blanchard (1997, p. 290) observed that almost all macroeconomists now work within a framework that combines three ingredients: intertemporal optimization, imperfect competition and sticky prices. This combination characterizes the current consensus view that is generally labelled as the New Neoclassical Synthesis (NNS), or the NNS triangle.

The NNS is epitomized by Michael Woodford's Interest and Prices (2003b), a book that explores the properties and welfare implications of monetary policy in the confines of the standard IS-AS-MP framework, where aggregate demand (IS) is derived from the representative household's intertemporal utility maximization, and aggregate supply (AS) is expressed in terms of a New Keynesian Phillips curve, based on imperfect competition and price rigidities. The model is closed by a reaction function of monetary policy (MP), typically a Taylor rule. Woodford (2003b, ch. 4) describes the model as "neo-Wicksellian", since the IS relation nests the real interest rate associated with potential output and the resulting (possibly zero) inflation rate the "natural rate of interest" in Wicksell's diction. Accounting for stochastic changes of this rate that follow from shocks to technology and preferences, the evolution of the economy over time is represented as a dynamic stochastic general equilibrium (DSGE) process. As a consequence of sticky prices, any gap between the market real interest rate (the nominal rate minus expected inflation) and the natural rate generates gaps in output and inflation with respect to their optimal values. These gaps, which entail welfare losses, can be reduced by appropriately designed interest-feedback rules on which the central bank operates.

This apparatus is clearly reminiscent of Knut Wicksell's Interest and Prices (1898). Referring to Wicksell and his followers Friedrich A. Hayek, Erik Lindahl and Gunnar Myrdal, Woodford (2003b, p. 5) claims "to resurrect a view that was influential among monetary economists prior to the Keynesian revolution". Moreover, by setting the focus on output effects of false positions of the market rate of interest, his version of the NNS appears to bring a common theme of Wicksellian and Keynesian theories back to the forefront of modern macroeconomics.

However, Wicksell and his followers, as well as Keynes, did not work

\footnotetext{
${ }^{1}$ For a similar history of 20th Century macroeconomics see Woodford (1999).
} 
within the NNS triangle. They normally used the assumption of "free competition". The stickiness of prices and wages played, at most, a subordinate role in their explanations of macroeconomic fluctuations. Their key "deviation from the standard perfect competition model" was an imperfection of the price mechanism in the capital market, not in the goods or labour markets. Even though they differed in their conceptual frameworks, both Wicksell and Keynes set the focus on the causes and consequences of misalignments of the market rate of interest with the rate, at which the plans of real investors (business firms) and financial investors (savers, wealth-holders) would be fully coordinated ${ }^{2}$. Intertemporal disequilibrium mattered to Wicksell and Keynes, not because of quantity rationing, but because, as long as the market real rate of interest is at the "wrong level", the economy will be driven away from its intertemporal-equilibrium path in a cumulative process of changes in prices and/or output at which capital and goods markets clear $^{3}$. They also shared the view that price and wage flexibility would not per se eliminate the effects of wrong interest rates nor induce their correction. Describing the "individual experiment" of optimal household planning, as in the NNS, was therefore not considered sufficient to determine the time paths of output and inflation. The "market experiment" i.e. the relative speeds and sizes of output and price adjustments, when intertemporal equilibrium is disturbed by interest-rate misalignments requires explicit analysis of the resulting shifts in the budget constraints ${ }^{4}$. Therefore, by way of contrast with the NNS triangle of intertemporal optimization, imperfect competition and sticky prices, a "Wicksell-Keynes (WK) triangle" can be described by the key words "intertemporal coordination",

\footnotetext{
${ }^{2}$ In Wicksell's bank-centred credit economy, it is the bank's lack of information about the full-employment-equilibrium, or "natural", rate of interest that causes the misalignments of the market rate. In Keynes's monetary economy, it is the liquidity preference of wealth holders in view of uncertainty about returns to investments that drives a wedge between the two rates. While Keynes had made use of Wicksells natural-rate concept in his Treatise (1930), he criticized it in the General Theory (1936, p. 183, 242-44) for its underlying loanable-funds view, but retained the reference to a benchmark rate that would be compatible with full employment. His shift towards liquidity-preference theory has led Leijonhufvud (1981) to argue that Keynes lost his "Wicksell Connection" when writing the General Theory. However, in the wider sense of coordination failures of the interest-rate mechanism, Leijonhufvud draws a dividing line between Wicksell and Keynes on the one hand, and the Keynesians of the old Neoclassical Synthesis whose explanations of macroeconomic fluctuations revolve around price and wage rigidities, on the other. Here we follow the same line with regard to the New Keynesians in the NNS.

${ }^{3}$ Wicksell (1898) restricted his analysis of the cumulative process to changes in the price level, whereas Keynes (1936) discussed cumulative changes of output, though neither of them denied that these processes involve changes in both output and prices. Lindahl (1930) and Myrdal (1931) analysed combinations of both, whereas Hayek (1931) described a change in the structures, not the levels, of prices and production. As we shall see, changes in all these dimensions coexist.

${ }^{4}$ For the distinction between individual and market experiments see that other book with interest and prices in its title: Patinkin (1989, ch.I:4).
} 
"imperfect capital markets" and "wrong interest rates".

Do the differences between the two triangles matter? Is there anything we can still learn form the WK triangle which is not in the NNS triangle? The standard answer is that macroeconomics, in the days of Wicksell and Keynes, lacked "conceptual rigour" in two regards. Fluctuations of output and price levels were not fully modelled in terms of optimizing behaviour, and the "imperfections" that explain them were not well understood (e.g., Blanchard, 2000, p. 1385-88; Woodford, 2003b, p. 5-6). The NNS is believed to have overcome these shortcomings by integrating price-setting behaviour into a DSGE framework. Woodford's insistence that the key results of Wicksellian theory can be replicated in DSGE models (Woodford, 2003b; Woodford, 2006, p. 196-97) suggests that the differences between the two triangles do not matter substantially, so that the older triangle could safely be left to historians.

The purpose of our paper is to challenge this view. In a more recent survey, Blanchard (2008) discusses several points where the standard NNS model should be improved to include a larger array of phenomena and provide better explanations. In this perspective, our point is that the boundaries of the NNS triangle hamper progress in dealing with relevant issues raised by the older theories. In particular, ignoring saving-investment imbalances seriously limits the explanatory scope of the NNS. Not only are these phenomena a logical implication of any theory based on the distinction between the market real interest rate and the Wicksellian natural rate. It can also be argued that informational imperfections in the capital markets and the consequent intertemporal imbalances play a major role in processes that generate macroeconomic instability, as testified by the global financial crisis that has recently developed (e.g. Borio and Lowe, 2002; Leijonhufvud, $2008)^{5}$.

In the following, we therefore propose a modeling framework that reconstructs, with some rigour, the WK triangle. Our model is meant to be authentic, in the sense that it is made of components that were available at the times of Wicksell and Keynes, if not used or even devised by them. Even though we will provide textual evidence, our rendition is not, however, meant to be "true" to these writers in every detail. At the same time, we have devised the model to be closely comparable to the standard threeequations model of the NNS by means of current modeling techniques. In

\footnotetext{
${ }^{5}$ Saving-investment imbalances are ignored even in the NNS model which include fixed capital and investment (e.g. Woodford, 2003b, ch. 5; Casares and McCallum, 2000). One strand of earlier New Keynesian literature had set the focus on imperfect information and capital market failures (see, e.g., Greenwald and Stiglitz, 1987; Bernanke and Gertler, 1990). To the extent that its results have been incorporated into the NNS, they are not connected with the possibility of saving-investment imbalances and their intertemporal implications. The same applies to NNS extensions that include imperfect information and investment dynamics (see, e.g., Woodford, 2003b, ch. 5; Woodford, 2003a; Mankiw and Reis, 2003). We comment on these extensions below.
} 
this way, we highlight what Wicksell and Keynes knew about macroeconomics that might still be worth knowing, even though modern economists tend to exclude it from their consensus view. We demonstrate the explanatory potential of a synthesis of Wicksellian and Keynesian ideas that differs substantially from the Neoclassical Synthesis, Old and New.

The rest of the paper is organized in three parts. Section [2] provides a brief account of the standard NNS model (Woodford, 2003b, ch.4) that serves to draw attention to critical limitations of the new synthesis. We discuss its effective reduction to the intratemporal coordination of aggregate demand and supply, and its specific assumptions about market structures that must be inefficient enough to create the relevant output gaps, while excluding major logical implications of interest-rate misalignments, namely the causes and consequences of a mismatch of intertemporal consumption and production plans.

Section [3] introduces the model of an economy in the confines of the WK triangle. Prices are flexible, agents have forward-looking expectations, the economy has a nominal unit of account, and physical capital is represented by interest-bearing bonds traded in the capital market. The central bank is the only policymaker, taking control of the economy's nominal interest rate by trading bonds. Information is imperfect in the sense that no one in the market can directly observe the natural rate of interest, i.e. the real rate that would equate optimal saving and investment. This lack of information is sufficient to generate "interest-rate gaps" and intertemporal coordination failures between saving and investment.

The thrust of the model is that saving-investment imbalances, by way of forward-looking agents' allocations, generate an intertemporal spillover effect, in that they transmit the effects of present interest-rate gaps to present and future output and inflation. As a result, these variables diverge from their intertemporal equilibrium path, in a way that considerably modifies the dynamic properties of the system with respect to the standard NNS framework where this effect is not present. First, output and inflation gaps display the autocorrelated dynamic structure that is typically observed in the data, with no addition of further frictions and imperfections. Second, it is shown that the system displays three distinctive WK features. Given an interest-rate gap, the time paths of prices and output evolve as "cumulative processes", which are the result of the interplay of "deep parameters" rather than exogenous factors. The system will return to its intertemporalequilibrium path only when the interest-rate gap is closed and the resulting saving-investment imbalance is corrected. Hence, price (or wage) stickiness is not the core problem, price (and wage) flexibility not the general solution.

In section [4] we focus on the formation of inflation expectations and on their implications for the system's stability as well as monetary policy. Since the model allows us to analyse out-of-equilibrium dynamics that are beyond the scope of the NNS triangle, we can show how short-run rational expecta- 
tions (the standard assumption in the NNS world) amplify price and output dynamics and tend to destabilize the system, as argued by both Wicksell and Keynes. This result provides a consistent foundation for those two ideas of Wicksell that have been transplanted into the NNS theory of monetary policy namely, the idea that stability can be preserved by a "nominal anchor" in terms of a stable price level (or inflation rate) in which agents have reason to believe, and the idea that, to this effect, the nominal interest rate should be raised (lowered) as soon as the rate of inflation increases (decreases). In fact, we show that a simple "Wicksellian rule" for monetary policy that follows this prescription without any other informational requirements may display remarkable out-of-equilibrium virtues of system stabilization. We also demonstrate that, based on the theoretical framework of the WK triangle, this kind of rule has dynamic properties that stand in contrast with the NNS literature. In particular, stability requires that the inflation coefficient of the rule should have an upper bound. This implies that the so-called Taylor principle, which requires an overproportional interest-rate reaction to the inflation gap (e.g. Woodford, 2003b, ch. 3), is not necessary and may well be conducive to instability. Central banks may thus face a trade-off, not between inflation and output control, but between "small gaps" and "smooth paths" in the adjustment process. In the final section we draw the conclusions and point out in which directions the Wicksell-Keynes triangle may be further explored.

\section{The Limitations of the New Neoclassical Syn- thesis}

In this section we sketch the basic model of the NNS in its most influential version, as presented by Woodford (2003b), and discuss its analytical limitations to set the stage for the subsequent exposition of our alternative WK model.

\subsection{The core of the NNS model}

The NNS is based on a system of three equations that determines the shortrun dynamics of output, inflation and interest rates. Confining his version to the study of "small fluctuations around a deterministic steady state", Woodford (2003b, p. 243-47) describes it as a log-linear approximation of the conditions for intertemporal general equilibrium.

The first equation describes aggregate demand and resembles the IS curve of the old Neoclassical Synthesis, insofar as it displays a negative relation between current output and the current (real) interest rate. It is, however, entirely based on the representative household's consumptionsaving decision and obtained by log-linearizing the first-order condition of 
maximizing utility over time:

$$
x_{t}=E_{t} x_{t+1}-\sigma\left(i_{t}-E_{t} \pi_{t+1}-r_{t}^{*}\right)
$$

As intertemporal optimization is formulated in terms of deviations from the steady state, $x_{t}$ denotes the gap between actual output and the "natural rate of output", $\sigma$ is the (constant) intertemporal elasticity of substitution of aggregate spending, $i_{t}$ is the nominal interest rate $E_{t} \pi_{t+1}$ is the rational expectation of the inflation rate conditional on information available at time $t$. Finally, $r_{t}^{*}$ is the "natural rate of interest". This terminology refers to the fact that $r_{t}^{*}$ is the value of the market real interest rate, $i_{t}-E_{t} \pi_{t+1}$, that is consistent with the steady state value of the output gap, which is zero. As will be seen, $x^{*}=0$ is also consistent with zero inflation. By contrast, deviations of the market real interest rate from $r_{t}^{*}$ trigger non-zero output and inflation gaps. In other words, the natural rate of interest is "just the real rate of interest required to keep aggregate demand equal at all times to the natural rate of output" (2003b, p.248). The "natural rate of output" refers to a virtual equilibrium with price flexibility, i.e. to the output "one would have if prices and wages were not in fact sticky" (2003b, p.9).

The second equation describes aggregate supply by relating the output gap to inflation. The AS function is labelled "New Keynesian Phillips curve" (though little reference is made to the labour market), since actual inflation is proportional to expected inflation and the output gap,

$$
\pi_{t}=\beta E_{t} \pi_{t+1}+\kappa x_{t}
$$

with $\beta$ denoting a discount factor, and $\kappa$ a rigidity parameter. In order to introduce nominal rigidities, Woodford (2003b, ch.2) makes the assumption that consumer demand is met by the supply of a variety of differentiated, imperfectly substitutable goods. This allows firms to set prices in monopolistic competition, following the Dixit-Stiglitz (1977) model. Imperfect competition does not per se imply price rigidities, so it is assumed that prices are set in a staggered fashion. In the case of interest-rate shocks (changes in $i_{t}$ or $r_{t}^{*}$ in equation (2.1)), a significant fraction of firms will maximize profits by varying their output rather than prices. The value of the rigidity parameter $\kappa$ rises with the strategic complementarity of price-setting decisions, such that the output effects of shocks can become large and persistent.

The third equation describes the feedback of the interest rate to changes in inflation and output gaps, assuming that the central bank controls the representative nominal interest rate. Woodford $(2003 \mathrm{~b}$, p. 245$)$ writes the MP function in terms of a Taylor rule:

$$
i_{t}=i_{t}^{*}+\gamma_{\pi}\left(\pi_{t}-\pi^{*}\right)+\gamma_{x}\left(x_{t}-x^{*}\right)
$$

where $i^{*}$ is an intercept term that correspond to the nominal value of the natural interest rate, $r^{*}+\pi^{*}$, or NAIRI (non-accelerating-inflation rate of 
interest). The weight factors $\gamma_{\pi}$ and $\gamma_{x}$ describe the intensity of the interestrate reactions to deviations of actual inflation and the output gap from their target values. The target for the output gap is defined as the steady-state value consistent with the inflation target. Using (2.2), this implies that $x^{*}=\frac{1-\beta}{\kappa} \pi^{*}$, and ensures that $i_{t}=i_{t}^{*}$ whenever the inflation target $\pi^{*}$ is achieved. The MP function closes the model, permitting the determination of the endogenous variables $i_{t}, x_{t}$ and $\pi_{t}$.

The IS-AS-MP framework can thus be characterized as a synthesis of standard Neoclassical, Wicksellian and Keynesian ideas. The failure of the system to converge automatically on its natural rates of output and interest is ascribed to nominal rigidities outside the capital market, as in the "classically" neoclassical approaches of Cassel (1918) and Pigou (1933), or in the old Neoclassical Synthesis á la Modigliani (1944). As in Keynes (1936), output adjustments accord with aggregate demand and precede, or even prevent, price adjustments, such that the latter do not automatically restore the optimal position of the system. As in parts of the Wicksellian literature, the "neutrality of money" 6 is not an automatic outcome of market processes, but requires a specific political strategy of interest-rate feedbacks to changes in the price level and/or output.

\subsection{Some implications of the model}

In the following we draw attention to assumptions in the basic "neo-Wicksellian" model, and indeed in much of the NNS literature in general, that limit the scope of the analysis of output gaps. Here we discuss only those that are most important for the contrast with the alternative Wicksell-Keynes model presented in the following section ${ }^{7}$.

It should be noted that the standard formulation of the IS relation (in equation (2.1)) implies that aggregate demand consists just of consumption. As Woodford (2003b, p. 242) points out, the model "abstracts from the effects of variations in private spending (including those classified as investment expenditure in the national income accounts) upon the economy's productive capacity", so the model should be interpreted "as if all forms of private expenditure... were like nondurable consumer purchases" ${ }^{8}$. Thus $r_{t}^{*}$

\footnotetext{
${ }^{6}$ It may be argued that money is not a quantitatively well-defined concept, neither in Woodford (2003b) nor in Wicksell (1898, 1898a); see, e.g., Laidler (2006). Furthermore, Woodford seems to avoid to refer to the concept of neutrality of money, while Wicksell confined real effects to the small print. Yet, what is at stake here is the argument that monetary policy has the power to change interest rates such that both the price level and the structure of prices will be affected. Thus it can produce (or avoid) substantial effects of monetary policy on output and income distribution, as argued, for example, by Lindahl (1930), Hayek (1931) and Myrdal (1931).

${ }^{7}$ Other problematic assumptions, especially those pertaining to the monetary foundations of Woodfords model, are examined in Boianovsky and Trautwein (2006). Some of their implications will be discussed in sections [4] and [5] below.

${ }^{8}$ Woodford (2003b, ch. 5) extends the basic model to include fixed capital and the
} 
is best interpreted as the representative household's rate of time preference. If the market real interest rate rises, and if there is no corresponding shift in $r_{t}^{*}$, current consumption falls in favour of increased future consumption. The opposite occurs if $r_{t}^{*}$ rises and is not matched by shifts in the market real interest rate.

The simplifying exclusion of (net) investment has two implications. First, changes in consumption plans translate themselves into one-to-one changes in aggregate demand at each date. Second, the intertemporal coordination problem between future consumption (saving) and future production (investment), which is the key problem to be solved by the interest rate in general equilibrium theory, vanishes. The system is effectively reduced to the intratemporal coordination of current aggregate demand and supply in each period, essentially (to be) accomplished by the system of spot prices for goods.

Woodford (2003b, p. 71 and elsewhere) assumes that "markets must clear at all dates". It should be noted that the NNS uses a deviation from the "standard perfect competition model" contained in the AS function, and not in the IS relation to provide a mechanism that coordinates aggregate demand and supply continuously. The key "imperfection" is monopolistic competition, which in the macroeconomic literature is nowadays treated as a standard "source of inefficiency" (cf. Cooper, 2004). Even so this market structure allows firms to determine supply and set prices while consumers are always on their demand curve. In the spirit of Blanchard and Kiyotaki (1987), this is frequently interpreted as a resurrection of the Keynesian message that aggregate output is governed by aggregate demand, at least in the short run. However, if it is not simply postulated that aggregate demand always matches aggregate supply, further conditions must be satisfied to ensure that state. Thus it must be assumed that the households in the system own the firms, that they receive the firms' profits as part of their income, and that there are no distribution effects of output gaps and inflation that could feed back onto the latter. All this is implicit in the conventional assumption of the representative household. Finally, the model is based on the premise that households and firms have rational expectations of future output gaps and inflation. In this setting, the optimal plans are self-fulfilling, at least in the absence of shocks. Output gaps and inflation have no influence on the speed and extent to which information is incurred, processed and used for predictions.

Imperfect competition implies price-setting behaviour, which helps to introduce nominal rigidities. The latter do not automatically follow from the model of monopolistic competition. To define the natural rate of output, Woodford (2003b) actually uses the strong assumption of a monopolisti-

effects of the related investment dynamics, but the possibility of unplanned saving is excluded by assumption. 
cally competitive system with flexible prices, in which output growth would not substantially differ from that of a perfectly competitive system. This is the fictitious NNS benchmark for assessing the welfare losses that accrue from sticky prices. The existence of nominal rigidities in the goods markets is, in turn, crucial for generating suboptimal equilibria in the NNS framework. They are introduced with reference to menu costs that make profit-maximizing firms choose between price and output adjustments in response to disturbances that affect marginal costs (Woodford, 2003b, ch. 3). However, these menu costs and other components of the rigidity parameter in equation (2.2) are exogenously given.

The NNS triangle is thus a narrowly confined space, precariously based on specific assumptions, by which market structures are postulated that must meet conflicting requirements. On the one hand, they must be inefficient enough to generate the output gaps that form the control problem for the social planner, as embodied in (2.2), the Taylor rule for monetary policy. On the other hand, they must rule out all the saving-investment imbalances that were at the heart of the distinction between market rates and natural rates of interest in earlier macroeconomics. If there are financial markets constituted by independent borrowers and lenders, the consequence of the market real interest rate on loans being higher (lower) than the natural rate is that households wish to save more (less), whereas firms wish to invest less (more). Neither side of the market can achieve intertemporal equilibrium, and the constraints that follow from the interest-rate gap need to be examined as out-of-equilibrium dynamics. This problem was in the focus of Wicksellian and Keynesian economics in the early 20th Century, whereas it is not contemplated even in the models that endogenize investment into the NNS framework (such as Casares and McCallum, 2000; Woodford, 2003b, ch. 5). While the distortionary effects of sticky prices are the raison d'être of monetary policy in the NNS, Wicksell (1898) argued that interest rates should be brought under policy control, not because there is a lack of price flexibility in the goods markets, but because misalignments of interest rates may force prices to move out of equilibrium. Keynes (1936, ch. 19), too, emphasized that there is no automatism, by which price and wage adjustments in goods and labour markets could balance the effects of a misaligned market rate of interest; he stressed that price flexibility would actually tend to make things worse. In the following, we will examine these issues, which cannot be captured in the confines of the NNS triangle, while they can - with some rigour - be explored in the framework of the Wicksell-Keynes triangle.

\section{Modelling the Wicksell-Keynes Triangle}

In the following we present the basic model of an economy in the WK triangle. As it is conceived to highlight the differences between the macroe- 
conomics of saving-investment imbalances and the NNS triangle, the model leaves the internal differences between Wicksell and Keynes in the background. It is Wicksellian in that it retains the assumption of a natural interest rate as gravitation centre of the economy, with no consideration of liquidity preference. It is Keynesian in that real income adjustments occur as a direct implication of intertemporal disequilibrium, notwithstanding the flexibility of prices. Apart from being based on insights of Wicksell (1898) and Keynes $(1930,1936)$, the model includes features that were emphasized by other authors in the Wicksellian tradition, such as Lindahl (1930), Myrdal (1931) and Lundberg (1930, 1937).

\subsection{The basic setup}

The economy consist of three competitive markets (for labour, capital and output) and rational forward-looking agents. All exchanges take place in terms of a general unit of account of value $\frac{1}{P_{t}}$, where $P_{t}$ is the general price level. It is assumed that technology and consumer preferences take the specific forms, respectively, of a Cobb-Douglas production function and a logarithmic utility function. These specific restrictions are not necessary, but they are useful to obtain a manageable closed-form solution to the model, and to make it comparable to standard modern models ${ }^{9}$.

Hence, aggregate output $Y_{t}$, which consists of a homogenous good that can be consumed or used as input in the production process, is given by

$$
Y_{t}=K_{t}^{a} L_{t}^{b} \text { where } a+b=1
$$

where $K_{t}$ is the capital stock available at time $t$ and $L_{t}$ is the current input of labour. The share of output that is transformed into capital at time $t$ becomes operative in the production process only in the next period, $t+1$. Capital is fully depreciated within one period, so that

$$
K_{t+1}=I_{t}^{\prime}
$$

where $I_{t}^{\prime}=I_{t}+K_{t}$ is gross investment including capital replacement and $I_{t}$ is net investment.

\footnotetext{
${ }^{9}$ As to the "authenticity" of the model, the use of these "classically neoclassical" assumptions may be surprising, in particular to those who connect the ideas of Keynes and other post-Wicksellians to a fundamental critique of the neoclassical theory of income distribution. It should be noted, however, that Wicksell (1901, p. 128) was one of the pioneers of the concept of the Cobb-Douglas production function, using it to show that the exhaustion theorem (according to which aggregate output is exactly absorbed by aggregate income, if the prices of the production factors accord with their marginal productivity) is valid only if returns to scale are constant. That assumption is restrictive, but certainly no bigger "as if" than the NNS assumption of an insignificant wedge between total output under imperfect competition with flexible prices and its perfect-competition counterpart (see above, section [2.2]).
} 
Firms are price takers and seek to maximize their expected stream of profits, given (3.1) and their costs in terms of the income-distribution constraint:

$$
E_{t}\left(\sum_{s=0}^{\infty} Y_{t+s}-w_{t+s} L_{t+s}-R_{t+s} K_{t+s}\right)
$$

where for each period $t, w_{t}$ is the real wage rate and $R_{t} \equiv 1+r_{t}$ is the real gross return purchased at time $t-1$. For each period $t$, firms' programmes consist of the choice labour $L_{t}^{*}$ for current production, and the capital stock $K_{t+1}^{*}$ for the next one.

In the labour market, workers and firms bargain over a real wage before production takes place, but labour contracts are in nominal terms, $W_{t}$. The nominal wage rate is obtained by way of indexation of the negotiated real rate $w_{t}^{*}$ to the expected price level $P_{t}^{e}$, where $e$ denotes an expectational variable (whose formation will be discussed below). Hence, denoting with $\pi_{t}$ the one-period inflation rate, the nominal wage rate results $W_{t}=w_{t}^{*} P_{t-1}(1+$ $\pi_{t}^{e}$. Subsequently, firms choose $L_{t}^{*}$ for production, observing the actual real wage rate given by the nominal rate deflated by the actual price level, $w_{t} \equiv$ $\frac{W_{t}}{P_{t}}$ or $w_{t}=w_{t}^{*} \frac{1+\pi_{t}^{e}}{1+\pi_{t}} 10$.

Firms can raise funds to invest in the capital stock by selling one-period bonds. By analogy with physical capital, they are time-indexed by maturity. Hence $B_{t+1}$ (in real terms) denotes bonds issued in period $t$ that bear a nominal interest rate $i_{t}$ with maturity in $t+1$. Likewise, the real rate of return to capital that firms pay to bond-holders in $t$ is $R_{t} \equiv \frac{1+i_{t-1}}{1+\pi_{t}}$, whereas the rate relevant to investment in $t$ is $R_{t+1} \equiv \frac{1+i_{t}}{1+\pi_{t+1}^{e}}$. As a result, $L_{t}^{*}$ and $K_{t+1}^{*}$ should satisfy the first order conditions of (3.3):

$$
\begin{gathered}
(1-a)\left(\frac{K_{t}}{L_{t}^{*}}\right)^{a}=w_{t} \\
a\left(\frac{L_{t}^{*}}{K_{t+1}^{*}}\right)^{1-a}=R_{t+1}
\end{gathered}
$$

Households hold claims to the capital stock and supply their whole labour force $L$ inelastically, which is normalized to unity $^{11}$. They choose a consumption plan $\left(C_{t+s} ; s=0,1, \ldots\right)$ in order to maximize their lifetime expected utility

$$
E_{t}\left[\sum_{s=0}^{\infty} \Theta^{-s} \ln C_{t+s}\right]
$$

\footnotetext{
${ }^{10}$ This representation of the labour market is akin to Keynes (1936, ch. 19).

${ }^{11}$ Whether the equilibrium employment is equal to, or less than, the total labour force, or how wages are determined, is immaterial here, or as implicit as the labour market is in Woodford's (2003b) version of the NNS. In analogy with the NNS one may allow for some "natural rate of unemployment" that creates a reserve capacity of labour. On the implications of this assumption see our discussion of the WK model in section [4] below.
} 
given the constant rate of time preference $\theta>0, \Theta \equiv(1+\theta)$, and the dynamic budget constraint:

$$
B_{t+1}=H_{t}+R_{t} B_{t}-C_{t}
$$

Here $H_{t}=w_{t} L_{t}$ is labour income, $B_{t}$ is the real stock of bonds representative installed capital, and the operator $E_{t}(\cdot)$ denotes forward-looking expectations, conditional upon information available at time $t$. Consequently $B_{t+1}-B_{t}=S_{t}$ is net saving, expressed as real purchases of bonds. Given their utility function (as in (3.6)), the households' optimal consumption as of time $t$ is expressed as

$$
C_{t}=E_{t}\left[\frac{C_{t+1}}{R_{t+1}} \Theta\right]
$$

In order to insulate the macroeconomic effects of interest-rate gaps, the analysis should start at a point in which the economy is in intertemporal general equilibrium (IGE). It is easily seen that equations (3.1), (3.4), (3.5) and (3.8), given $L^{*}=1$ and $\pi_{t+1}^{e}=\pi_{t}^{e}=\pi_{t}$, yield the steady-state solution, where the real return to capital is $R_{t+1}=\Theta=R^{*}$, so that for all $t, C_{t}=C^{*}$, $B^{*}=K^{*}$ and $Y^{*}=H^{*}+R^{*} K^{*}$. Note that $S_{t}^{\prime}=I_{t}^{\prime}=K^{*}$, and once account is taken of capital replacement, net investment and saving are nil ${ }^{12}$. Hence $R^{*}$ is also the natural interest rate that equates optimal saving and investment.

What remains to be determined is the price level and the steady-state inflation rate. As is well-known, a competitive general equilibrium model like the present one leaves the price level and its changes undetermined. The usual practice has long been to introduce a special "monetary equation" that pins down the price level corresponding to the general-equilibrium output level. This is actually the critical point where Wicksell departed from the classical tradition of the quantity monetary equation and introduced his interest-rate theory of inflation. Once the nominal interest rate is in place, the intertemporal general equilibrium characterized above also implies that $\left(1+i_{t}\right)=R^{*}\left(1+\pi_{t+1}^{e}\right)$ should hold for all $t$. This relationship is also known as "Fisher equation", and is in fact plugged into the NNS model (equation (2.1)). Yet, from a Wicksellian point of view, the Fisher equation presents two problems. First, if it is employed to pin down the nominal interest rate, it still leaves the price level determination unresolved, and the expected inflation term on the right-hand side is left hanging on its own bootstraps. Second, if expected inflation rate is to be determined by postulating an exogenous nominal interest rate, it should be high as long as the nominal interest rate is high relative to the natural rate, and vice versa - in contradiction with the conclusions of Wicksell, the NNS and common sense (but argued by McCallum, 1986). The Fisher equation holds in intertemporal

\footnotetext{
${ }^{12}$ Abstracting from techinal progress or technical shocks, this is in fact a Sidrausky-type steady state, where the key allocational variable in the capital market is just the rate of intertemporal consumer preferences, $\Theta$.
} 
equilibrium, but in the construction of a consistent interest-rate theory of the general price level, it cannot be taken to hold continuosly. Such a theory requires three building blocks: (i) the market determination of the nominal interest rate, (ii) the determination of inflation expectations, and (iii) the interaction between the two. The whole should be analysed in terms of an intertemporal disequilibrium process to check whether it eventually converges to the Fisher equality and how much inflation will be generated in the process. This was in fact the research agend of Wicksell and Lindahl.

Since this is the most critical nexus in the whole construction, we wish to proceed step by step from the simplest hypotheses concerning the determination of the nominal interest-rate and of inflation expectations to alternative hypotheses drawing on Wicksell and the subsequent literature. In analogy with Wicksell (1898), Lindahl (1930) and Keynes (1930; 1936), we begin with a simplified monetary system that consist of a central bank, representative the system of bank loans and deposits as a whole. In a Keynesian twist of this assumption, the central bank seeks to gain control over the nominal interest rate $i_{t}$ by buying and selling bonds in the open market. Pegging the nominal rate, the central bank is ready to create or retire base money (the counterpart of bonds) to the extent that is necessary to clear the market ${ }^{13}$. All agents form their expectations of the inflation rate, consider their objective functions and constraints, and make their plans accordingly. At this stage, we simply posit that all agents believe in a time-invariant "normal" rate, $\pi_{t+1}^{e}=\pi^{e}=\pi^{*} 14$. Finally, exchanges occur in all markets, and $\left[Y_{t}, \pi_{t}\right]$ are realized.

\subsection{Three-gap analysis}

To begin with, we examine the implications of a gap arising between the market real interest rate and the natural rate with respect to the intertemporal general equilibrium (IGE) characterized above. Given $\pi^{*}$, a gap between $R_{t+1}$ and $R^{*}$ can arise owing to a nominal cause, where $i_{t}$ is set or changed inconsistently with $R^{*}\left(1+\pi^{*}\right)$, or to a real cause, where a change in $R^{*}$ is not matched by a change in $i_{t}$. Which of the two causes originates the gap is immaterial here. The key issue is how the system behaves as long as

\footnotetext{
${ }^{13}$ Admittedly, this representation can be viewed as a short-cut with respect to the fullblown analysis of the banking sector by Wicksell. However, the key point remains, as the central banks' willingness to create (destroy) reserves at the given nominal interest rate corresponds to the aggregate effects of private banks lending.

${ }^{14}$ The concept of the "normal" value of a variable was widely used as point of reference expectations by Wicksell, Lindahl, Keynes and pre-Lucasian economists in general. It normally referred to the long-run average value observed for the variable in question, expected to prevail in future states of rest of the system. For simplicity, this information about inflation is taken here as the pre-determined (possibly zero) value $\pi^{*}$. If it also results to be the steady-state solution for inflation, then $\pi^{*}$ is also the "long-run" rational expectation of the inflation rate.
} 
$R_{t+1} \neq R^{*}$. What Wicksell and Keynes had in mind is, in modern terminology, "trading at false price" (which should not be confused with quantity rationing). By pegging $i_{t}$, the central bank keeps clearing the bond market: as long as $R_{t+1}>R^{*}$, it meets excess saving with extra-sales of bonds; the converse applies in the case of $R_{t+1}<R^{*}$. The crucial consequence of this can be expressed in the following proposition (see also the Appendix):

Proposition 1 Given $R_{t+1} \neq R^{*}$, although the bond market clears, the ensuing levels of saving and investment are not consistent with the clearing of the goods market, neither in $t$ nor in the subsequent periods, at the IGE values of output and and inflation.

The proof of this proposition is a well-known implication of Walras Law, which yields the constellations in the goods market that are associated with $R_{t+1} \neq R^{*}$ in the bond market:

\begin{tabular}{|l|c|c|}
\hline Bond Market (at time $t)$ & $R_{t+1}>R^{*}$ & $R_{t+1}<R^{*}$ \\
\hline Output Market (at time $t$ ) & exc. supply & exc. demand \\
Output Market (at time $t+1$ ) & exc. demand & exc. supply \\
\hline
\end{tabular}

Consider the typical Wicksellian case $R_{t+1}<R^{* 15}$. In this case, firms are allowed to invest more (adding physical capital to their net worth) than households are actually ready to save (adding more bonds to their wealth). The consequence is excess demand in period $t$ due to net investment and excess supply in period $t+1$, corresponding to a production capacity (due to net investment in $t$ ) that is not matched by planned consumption (low saving in $t$ ). If we abide with the principle that "markets always clear", then we should explain how can these intra- and inter-temporal inconsistencies among plans can be brought into equilibirum. The solution lies in the following proposition (proof in Appendix):

Proposition 2 Given $R_{t+1} \neq R^{*}$ in any period $t$, there exists one single sequence of realizations of output and inflation in $t$ and owards that clears the goods market.

In consideration of Proposition 1, such a sequence cannot be identical to the one that would obtain in intertemporal equilibrium, with $R_{t+1}=R^{*}$. In fact, if we follow Woodford's procedure of relating actual output and inflation at each point time, $Y_{t}, \pi_{t}$, to their respective IGE value, $Y^{*}, \pi^{*}$, we obtain the following expressions in terms of "gaps" (see Appendix):

$$
\begin{gathered}
\hat{Y}_{t}=\left(\hat{R}_{t+1}\right)^{-\frac{1}{1-a}}, \hat{Y}_{t+1}=\left(\hat{R}_{t+1}\right)^{-\frac{a}{1-a}} \\
\hat{\Pi}_{t}=\left(\hat{Y}_{t}\right)^{\frac{a}{1-a}}, \hat{\Pi}_{t+1}=\left(\hat{Y}_{t+1}\right)^{\frac{a}{1-a}}
\end{gathered}
$$

\footnotetext{
${ }^{15}$ Keynes was more concerned with the opposite case, but the mechanism is the same.
} 
where $\hat{Y}_{t} \equiv \frac{Y_{t}}{Y^{*}}, \hat{R}_{t+1} \equiv \frac{R_{t+1}}{R^{*}}$ and $\Pi_{t} \equiv \frac{1+\pi_{t}}{1+\pi^{e}}$.

To understand these results consider our previous example with $R_{t+1}<$ $R^{*}$, i.e. the case of excess investment, with the central bank buying extra bonds in the market. This case makes households in period $t$ reckon a real value of wealth (bonds) smaller than the value of capital the bonds are supposed to represent. The interest-rate gap affects the accounting of real resources in the economy, and the economy needs a correction of the intertemporal resource distribution. To this effect, output (real incomes accruing to households) should be higher along the consumption path of households. Correspondingly, in order to induce profit-maximizing firms to increase output with respect to $Y^{*}$, the inflation rate, too, should be (unexpectedly) higher than the normal rate embedded in nominal wage contracts. Note that unexpected inflation is an integral part of the process, in the sense that, as long as there exist interest-rate gaps, and hence output gaps, the economy must be off whatever inflation path expected by agents. As a matter of logic implied by the rational-expectations hypothesis, agents form inflation expectations in consistence with their plans. However, as these plans are frustrated in the goods market, the related expectations of inflation will be falsified.

\subsection{A log-linear version}

To facilitate comparison with the NNS, we now present a log-linear version of the previous model. Let us consider the relationship between the market real interest rate and the natural rate in any period $t$, and let us begin with the IS function (3.9). Since the output gaps in $\mathrm{t}$ and in subsequent periods share the common factor $\frac{R_{t+1}}{R^{*}}$, they can also be expressed in a single reduced form that, in its log version with Woodford's notation, yields ${ }^{16}$ :

$$
\hat{y}_{t+1}=\rho \hat{y}_{t}-\alpha\left(i_{t}-\pi^{*}-r\right)
$$

There is a clear analogy with the IS (equation (2.1)) in the NNS model, but there are substantial differences, too. Equation (3.11) describes output dynamics off the IS schedule that corresponds to the IGE in the way explained above. Due to their intertemporal "feed-forward effect" (which is not captured by the NNS model), interest-rate gaps generate time series of output gaps that display (a) dependence on the lagged value of interest-rate gaps, and (b) some degree of (spurious) serial correlation or "inertia" measured by parameter $\rho$. Notably, a dynamic structure like (3.11) is consistent with recurrent empirical estimates of IS equations, which almost invariably find both (a) and (b) - two features that are not easily accommodated in the

\footnotetext{
${ }^{16}$ Let $\hat{Y}_{t}=Z_{t}^{m}$ and $\hat{Y}_{t+1}=Z_{t}^{n}$. Then it is possible to write $\hat{Y}_{t+1}=Y_{t}^{\rho} Z_{t}^{\alpha}$ for linear combinations of the parameters $\rho$ and $\alpha$, such that $\rho m+\alpha=n$.
} 
framework of the NNS ${ }^{17}$. We shall see that this specification entails considerable differences also in the dynamic properties of the economy. Let us now turn to the AS function (3.10) in its straightforward log-version:

$$
\hat{\pi}_{t+1}=\beta \hat{y}_{t+1}
$$

Again there are analogies, but also important differences in comparison with the NNS model. The function describes the price/output dynamics off the AS curve that is associated with the IGE, with $\beta=\frac{a}{1-a}$ being the deviation of current from expected inflation that is necessary for competitive firms to supply one unit of profit-maximizing output above/below potential. Consequently, the key to the inflation gap is the difference between the actual rate and its expected value ex ante rather than the rate expected for the future. The flavour of (3.12) may in that sense be more Lucasian than New Keynesian, but it captures the essence of Wicksell's idea of inflation as an expectational disequilibrium phenomenon combined with Keynes's idea of the labour market being affected by the unwarranted coincidence between nominal wage contracts and their real value. It is clear that at this point a consistent model calls for additional hypotheses about expectation formation and interest-rate determination. Before proceeding to these two steps, it is useful to check the dynamic properties of the two-equation system (3.11)-(3.12).

\subsection{A model check}

Equations (3.11) and (3.12) form a first-order difference system in the two gaps $\left[\hat{y}_{t+1}, \hat{\pi}_{t+1}\right]$ with exogenous nominal interest rate and expected inflation. This formulation is sufficient for a preliminary check of its dynamic properties, compared with Wicksell's theory of cumulative processes of inflation and Keynes's restatement of that theory in terms of output.

To begin with, it is convenient to define the variable $i \equiv r^{*}+\pi^{*}$ in the IS function (3.11), the nominal value of the natural interest rate. It corresponds to Wicksell's "normal rate of interest" (Wicksell, 1898, p. 82), in modern parlance: the NAIRI, which provides the IGE benchmark for the nominal interest rate $i_{t}$. Let $\hat{i}_{t}=i_{t}-i^{*}$ be the nominal interest-rate gap (exactly equivalent to the real gap). We thus have the following non-homogeneous system:

$$
\left[\begin{array}{l}
\hat{y}_{t+1} \\
\hat{\pi}_{t+1}
\end{array}\right]=\left[\begin{array}{cc}
\rho & 0 \\
\beta \rho & 0
\end{array}\right]\left[\begin{array}{l}
\hat{y}_{t} \\
\hat{\pi}_{t}
\end{array}\right]+\left[\begin{array}{c}
-\alpha \\
-\beta \alpha
\end{array}\right]\left[\hat{i}_{t}\right]
$$

\footnotetext{
${ }^{17}$ Attempts to fix the problem usually amount to injecting additional "frictions" into the markets, or postulate limits to the information-processing capacity of agents. Examples of inertial market frictions can be found in Woodford (2003b, ch.5) and Aghion et al. (2004). Informational imperfections have been investigated by Mankiw and Reis (2003), Sims (2003), Orphanides and Williams (2006). The consideration of the savinginvestment imbalances, as in the original Wicksellian macroeconomics, may be seen as a more straightforward approach to serial correlation.
} 
For any initial value $\hat{i}_{0} \neq 0$, this possesses the following steady-state solutions:

$$
\begin{aligned}
& \hat{y}=-\frac{\alpha}{1-\rho} \hat{i}_{0} \\
& \hat{\pi}=-\frac{\beta \alpha}{1-\rho} \hat{i}_{0}
\end{aligned}
$$

That is to say:

Proposition 3 A permanent interest-rate gap determines permanent output and inflation gaps. Conversely, the output and inflation gaps are nil only if the interest-rate gap is also nil (see also Leijonhufvud, 1981, p.136).

Proposition 4 If $\rho \in[0,1]$ output and inflation converge monotonically to, and remain locked in, the values given by (3.13) and (3.14), with both output and inflation being inefficiently high or low, and being inconsistent with their IGE expected values.

These two propositions capture the essence of WK cumultative processes as disequilibrium phenomena.

Consider the typical Wicksellian case where $\hat{i}_{0}<0$ and the intial inflation is zero so that $\pi^{*}=0$. Consequently, the price level is set on the path given by (3.14), growing indefinitely at a constant rate. In the Wicksellian literature, cumulative processes are, however, often associated with non-monotonic, accelerating inflation rates ${ }^{18}$. Our assumption that inflation expectations are held constant at $\pi^{*}=0$ corresponds to a stage that Wicksell describes as a relatively favourable situation where expectations remain anchored to the "normal" price level, and changes are deemed temporary. However, as long as the interest-rate gap is not closed, changes in the price level persist. This raises the questions of how expectations are revised, and how the revision mechanism impinges upon the dynamic process - problems that will be reconsidered below.

Our model shows that a cumulative process unfolds on the real side of the economy, too. This illustrates the Keynesian point that saving-investment imbalances are misallocations that require real resource adjustments, irrespective of the degree of flexibility of prices. In a typical Keynesian situation with $\hat{i}_{0}>0$, resulting from a fall in the "marginal efficiency of capital", equation (3.13) indicates that output will converge to a steady state characterized by a permanent gap with respect to the IGE. At that point of effective demand, the goods market clears, while the output gap implies unemployment above the natural rate (if there is any).

\footnotetext{
${ }^{18}$ Wicksell (1922, p. XII n.1) explained this as part of the mechanism of expectations formation: "[A]s long as the change in prices ... is believed to be temporary, it will in fact remain permanent; as soon as it is considered to be permanent, it will become progressive, and when it is eventually seen progressive it will turn into an avalanche".
} 
It might be argued that our model is not fully true to Wicksell, who envisaged the cumulative process as a mechanism of price adjustments only, nor to Keynes, who emphasized that aggregate demand and aggregate supply could contract in a multiplier process at an unchanged price level. However, these mutually exclusive views oversimplify the processes driven by savinginvestment imbalances in a flex-price economy, as shown by our model; and they oversimplify the positions of the two original authors.Wicksell (1898, p. $142-3 ; 1915$, p. 1955) did not deny that cumulative inflation is accompanied by changes in output; he just considered them to be non-cumulative and, hence, less relevant ${ }^{19}$. Nor did Keynes exclude that the price level changes when the real-income mechanism is at work (e.g.,1936, ch. 19). He only pointed out that downward price (and wage) flexibility would tend to make things worse and that, on the other hand, price level stability would not be a sufficient condition for full-employment equilibrium, at which the money rate of interest would accord with the natural rate, or "neutral rate" in Keyness diction (1936, p. 243).

As a synthesis of Wicksellian and Keynesian ideas the essence of our model is to demonstrate that booms and slumps as well as inflation and deflation, are intertemporal disequilibrium phenomena in three distinct, but interconnected, meanings: (i) excess investment or saving is accommodated at the "wrong" real interest rate, (ii) the goods market clears at the "wrong" levels of output and inflation, and (iii) the expected rate of inflation is "wrong" with respect to actual inflation.

\section{Expectations and stabilization in the Wicksell- Keynes Triangle}

Our basic WK model warrants further exploration with regard to the formation of expectations and its consequences for monetary policy. In the basic version we assumed exogenous expectations that reflect the "normal" growth rate (zero or positive) of the price level. The problem with this assumption is that, in the case of a (persistent) interest-rate gap, expectations of return to normality will be systematically falsified. While modern economists tend to rule this out by focusing exclusively on states of the economy in which expectations are statistically correct, Wicksell, Keynes and many others in their

\footnotetext{
${ }^{19}$ Wicksell's theory of the cumulative process is often interpreted in terms of the traditional neoclassical view that perfectly competitive markets would keep resources fully employed to the extent that output cannot be increased and a low market interest rate could only generate inflation. However, the key to such processes is that firms are allowed to over-borrow and demand additional capital. It is only an extreme idea of full employment that may preclude this demand from being met by mobilizing or relocating resources within the economy. This was a major objection that Lindahl, Myrdal and Hayek raised against Wicksell from a multi-sector general equilibrium point of view (see Boianovsky and Trautwein, 2006; 2006a).
} 
circles were concerned with tracking the economy's behaviour outside expectational equilibrium. Nevertheless, continuous under- or over-estimation of inflation was deemed an untenable assumption even in their times. Wicksell (1915, p. 196; 1922, p. XII) therefore introduced the hypothesis of learning in the cumulative process that shifts expectations from static to adaptive to forward-looking and eventually "rational" in the sense of self-fulfilling ${ }^{20}$. As we cannot go deeper into the literature here, we confine ourselves to examining a noteworthy coincidence between the expectation mechanisms considered in the Swedish school and the way in which rational expectations are introduced in the standard NNS model.

\subsection{The troublesome role of rational expectations}

An analogy between the Swedish school and modern macroeconomics can be stated in terms of short-run rational expectations, the (statistically correct) anticipation in period $\mathrm{t}$ of the one-period inflation rate, $E_{t}\left(\pi_{t+1}^{e}-\pi_{t+1}\right)=0$, which implies $\pi_{t+1}^{e}=E_{t} \pi_{t+1}$. Even though we skip the learning process, we can endogenize expectations in a way that Wicksell regarded as plausible, but also as worrysome. Unlike the NNS, he was not concerned with jumps from one equilibrium to the next, but with the convergence of expectations in a disequilibrium process. Therefore, it is useful to re-examine the WK model in the case of an economy where a fraction $\delta$ of the agents holds short-run rational expectations of inflation, $E_{t} \pi_{t+1}$, whereas a fraction $1-\delta$ sticks to the expectation of "normal" inflation, $\pi^{*}$. To this effect, we replace $\pi^{*}$ in equations (3.11) and (3.12) with $\delta \pi_{t+1}+(1-\delta) \pi^{*}$, while maintaining that $\hat{\pi}_{t+1}=\pi_{t+1}-\pi^{*}$. As a result,

$$
\begin{gathered}
\hat{y}_{t+1}=\rho^{\prime} \hat{y}_{t}-\alpha^{\prime} \hat{i}_{t} \\
\hat{\pi}_{t+1}=\beta^{\prime} \hat{y}_{t+1}
\end{gathered}
$$

where

$$
\alpha^{\prime}=\alpha \frac{1-\delta}{1-\delta(1+\alpha \beta)}, \rho^{\prime}=\rho \frac{1-\delta}{1-\delta(1+\alpha \beta)}, \beta^{\prime}=\frac{\beta}{1-\delta}
$$

The steady-state solution for $\left[\hat{y}_{t+1}, \hat{\pi}_{t+1}\right]$ can simply be restated as follows

$$
\begin{aligned}
& \hat{y}=-\frac{\alpha^{\prime}}{1-\rho^{\prime}} \hat{i}_{0} \\
& \hat{\pi}=-\frac{\beta^{\prime} \alpha^{\prime}}{1-\rho^{\prime}} \hat{i}_{0}
\end{aligned}
$$

\footnotetext{
${ }^{20}$ Lundberg (1930) actually used the notion of "rational expectations". Lindahl (1930, p. 147) had it in the sense of "individual anticipations of coming price developments" that are "the causes of the actual developments themselves". For a modern treatment of the learning process in the cumulative process see Howitt (1992).
} 
Though similar to (3.11) and (3.12), these new solutions are ambiguous with regard to their sign, magnitude and stability, essentially in connection with parameter $\delta$. In general, we find that:

i the coefficients of $\hat{y}$ and $\hat{\pi}$ increase with $\delta$ in absolute value; forwardlooking expectations amplify the deviation of the steady state from the IGE path,

ii for $\hat{y}$ and $\hat{\pi}$ to maintain the normal negative relationship with $\hat{i}_{0}, \delta$ should be bounded at $\delta<\left(1+\frac{\alpha \beta}{1-\rho}\right)^{-1}<1$; a higher share of forwardlooking expectations would invert the relationship between interestrate gap, output gap and inflation gap (e.g., a positive interest-rate gap would raise inflation permanently),

iii if $\delta$ satisfies the sign condition, the system also converges monotonically to $[\hat{y}, \hat{\pi}]$; if $\delta$ exceeds the sign condition, the system may take different trajectories (all with positive sign with respect to $\hat{i}_{0}$ ) some of which may be explosive,

iv the limit solution for $\delta \rightarrow 1$, is $[\hat{y}, \hat{\pi}]=\left[0, \hat{i}_{0}\right]$; in this case, the system "jumps" to an inflation gap equal to (and of the same sign of) the interest-rate gap, and forward-looking expectations are (self-)fulfilled.

These results illustrate the troublesome role of "smart" short-run expectations in cumulative processes in the traditions of Wicksell and Keynes. The problems arise in the IS function. Suppose again that $\hat{i}_{0}<0$, with the negative interest rate gap producing a positive output gap. As some agents anticipate higher inflation, the market real interest rate is reduced further, increasing the gaps, and so on. This "expectation multiplier" explains why short-run rational expectations are deviation-amplifying and why the cumulative process is bounded only if their weight is limited.

Recalling the discussion in section [3.1], it is worth stressing that the case of $\delta \rightarrow 1$ replicates the result of McCallum (1986), according to which any pegging of the nominal interest rate above or below the natural rate leads to price-level changes that carry the sign opposite of what Wicksell predicted. McCallum stressed that this is consistent with the Fisher equation and concluded that Wicksell's theory does not hold under rational expectations. However, starting from the Fisher equation as a basis for expectation formation, as McCallum does, is not a correct rendition of Wicksell's theory, in which the Fisher equation should be the end point of adjustments in a disequilibrium process. As can be seen from our treatment, McCallum's conclusion is valid only within the limits of uniformly held rational expectations (see also Howitt, 1992). 


\subsection{Endogenizing the interest rate and anchoring expecta- tions}

In view of the processes driven by saving-investment imbalances, Wicksell and Keynes raised two crucial consequential questions: how can interestrate gaps be closed? Can capital market forces take care of the problem or is a "visible hand" required? It is worth comparing answers from the WK triangle with those in the NNS triangle.

Wicksell was aware that, in the context of his theory, price-level stability would require two conditions to be met: the nominal interest rate must be connected to changes in the price level in a stabilizing way, and inflation expectations must be anchored by a norm against which price movements can be gauged. Wicksell (1898, ch. 11) interpreted the natural rate of interest, not as a variable that can be observed by anyone in the system, but as a hidden attractor of the system, where the latter is driven by agents reacting to observable market signals ${ }^{21}$. Explaining the observable co-movement of prices and interest rates ${ }^{22}$, as a first approximation, Wicksell $(1898$, p. 11318) argued that cumulative processes might be self-correcting, provided that commercial banks react to accelerating inflation by adjusting their lending rates to a level consistent with the (new) steady-state level of prices. This, however, requires that their expectations are anchored to a "normal" rate of inflation $^{23}$. Technically speaking, with reference to our WK model, Wicksell's first move consists of endogenizing the nominal interest rate, and hence the interest-rate gap. This operation transforms the non-homogenous system (4.1)-(4.2) into a homogeneous one, where all three gaps appear as endogenous variables. In general, one expects homogenous systems to have zero-gap solutions in the final steady state, which we are looking for. These solutions should include the "normal" inflation rate. In modern terminology, the aim is to define an "interest rate rule" that supports a determinate rational-expectations equilibrium. To address this issue, we may begin with a simple representation of an indexation mechanism, such as the following:

$$
i_{t+1}=i_{t}+\gamma\left(\pi_{t+1}-\pi_{t+1}^{e}\right)
$$

Starting from $i_{t}$, the interest rate will remain constant as long as inflation is in line with the expected rate, whereas it will increase (decrease) as inflation accelerates (decelerates). In a Wicksellian perspective, equation (4.5) can be interpreted as shorthand either for the price-level correlation of the interest rate in the market process, or for the policy prescription that can be found in Wicksell's following formulation of a simple interest-rate rule:

\footnotetext{
${ }^{21}$ We owe this point to Axel Leijonhufvud.

${ }^{22}$ This phenomenon was later described as "Gibson paradox" by Keynes (1930, p. II: 198-208).

${ }^{23}$ Note that, apart from the central bank, there are no forces in the NNS model that would make the interest rate change with inflation.
} 
"So long as prices remain unaltered, the [central] banks rate of interest is to remain unaltered. If prices rise, the interest rate is to be raised, and if prices fall, the rate of interest is to be lowered; and the rate of interest is henceforth to be maintained at the new level, until a further movement of prices calls for a change in one direction or the other". (Wicksell, 1898a, p. 102)

The key difference between such a strategy of monetary policy and marketbased interest-rate determination can only lie in the specification of inflation expectations. It is obvious that the interest-rate mechanism of equation (4.5) is not sufficient to obtain the homogenous transformation as long as $\pi_{t+1}^{e} \neq \pi^{*}$. Yet this is precisely the problem with unregulated market processes examined in the previous paragraph. Hence, there is a clear role for the coordination of inflation expectations through an interest-rate rule for monetary policy. This can be derived as follows:

$$
i_{t+1}=i_{t}+\gamma\left(\pi_{t+1}-\pi^{*}\right)
$$

Subtracting the (constant) NAIRI $i^{*}$ from both sides of equation (4.6), we have

$$
\hat{i}_{t+1}=\hat{i}_{t}+\gamma \hat{\pi}_{t+1}
$$

Equations (4.1), (4.2) and (4.7) form the homogeneous system in the three gaps $\left[\hat{y}_{t+1} ; \hat{\pi}_{t+1} ; \hat{i}_{t+1}\right]$, which we are looking for:

$$
\left[\begin{array}{c}
\hat{y}_{t+1} \\
\hat{\pi}_{t+1} \\
\hat{i}_{t+1}
\end{array}\right]=\left[\begin{array}{ccc}
\rho^{\prime} & 0 & -\alpha^{\prime} \\
\rho^{\prime} \beta^{\prime} & 0 & -\alpha^{\prime} \beta^{\prime} \\
\gamma \beta^{\prime} \rho^{\prime} & 0 & 1-\gamma \beta^{\prime} \alpha^{\prime}
\end{array}\right]\left[\begin{array}{l}
\hat{y}_{t} \\
\hat{\pi}_{t} \\
\hat{i}_{t}
\end{array}\right]
$$

Clearly, this system admits of a zero-gap steady-state solution. Thus our model demonstrates a point argued by Wicksell $(1898,1915)$ and even more forcefully by Lindahl (1930): the central bank must announce an inflation norm, say $\pi^{*}$, and then gear the interest rate appropriately, in order to provide an anchor for long-run rational expectations, by which the system is stabilized.

Equation (4.7) can be regarded as a prototype of modern inflation targeting that we may call the Wicksellian rule, and it accords well with the NNS view of the central bank as "manager of expectations" (Woodford, 2003b, p. 15). However, the theoretical foundations of this consensus are substantially different and, as will be shown in the following, they yield strongly different conclusions for the design of monetary policy .

It might be objected that Keynes (1936) put forward an alternative explanation of interest-rate gaps (liquidity preference), an alternative mechanism of endogenous interest-rate adjustments (real balance effects) and an alternative view of monetary policy (quantity control of money supply). He also attached more importance to bond price expectations than to goods 
price expectations. These differences are important, as real balance effects and quantitative control came to predominate in the theory of monetary policy throughout most of the 20th century. However, seen from the vantage point of the WK triangle, there are substantial analogies as Keynes, like Wicksell, concluded that interest-rate gaps should not be left to unfettered market forces. He only used different ingredients to pursue the same "modelling strategy" as Wicksell, namely endogenizing the interest rate by way of monetary policy in order to realign the nominal interest rate to the rate that ensures saving-investment equilibrium at full employment ${ }^{24}$. Since our purpose here is to compare the WK model with the NNS model, we now concentrate on our Wicksellian interest-rate rule.

\subsection{Exploring the Wicksellian rule}

An endogenous interest-rate is a necessary, but not sufficient, condition for convergence to the zero-gap state. It is convenient to note that previous system can be reduced to the variables $\left[\hat{y}_{t+1} ; \hat{i}_{t+1}\right]$ since the path of $\hat{\pi}_{t+1}$ is fully determined by them. With this specification, the system presents two eigenvalues; convergence and stability require them to lie within the unit circle. Next, a simple boundedness condition on $\gamma$ is obtained.

Proposition 5 An endogenous interest rate indexed to the inflation-rate gap ensures convergence and stability with respect to the zero-gap steady state provided that the relevant inflation parameter is bounded within

$$
0<\gamma<\frac{2\left(1+\rho^{\prime}\right)}{\alpha^{\prime} \beta}
$$

This is obtained by applying the Schur Principle to the coefficient matrix of the relevant specification of the system ${ }^{25}$. It has some interesting implications.

The first implication is that the Wicksellian rule need not - and should not - specify reactions to both output and inflation gaps, since the two are positively correlated. Stabilizing inflation also stabilizes output, and vice versa. As we shall see, the crucial concern for monetary policy is not a trade-off between inflation and output, but the speed and amplitude of the adjustment process driven by the interest-rate policy.

The second implication of Proposition 5 is a contrast between the boundedness on $\gamma$ and the "Taylor principle", which prescribes an inflation coefficient with a lower bound equal to 1 (see, e.g., Woodford, 2003b, p. 253-54). The upper bound on $\gamma$ is the more binding, the more inflation is sensitive

\footnotetext{
${ }^{24}$ As shown by Tamborini (2006), there are in fact remarkable analogies between our system and a system in which the nominal interest rate is governed by a Keynesian LM function.

${ }^{25}$ If $A$ is the matrix, then, $1+\operatorname{tr}(A)+\operatorname{det}(A)>0,1-\operatorname{tr}(A)+\operatorname{det}(A)>0,1-\operatorname{det}(A)>0$.
} 
to interest-rate gaps (as measured by $\alpha^{\prime} \beta^{\prime}$ ), and the more short-term inflation is anticipated (as measured by $\delta$ ). The contrast between Proposition 5 and the Taylor principle arises from the differences in the microfoundations underlying the IS relation. We have seen that, in the out-of-equilibrium dynamics, interest-rate gaps affect present and future output and inflation gaps. As a consequence, gentle, rather than aggressive, interest-rate corrections are required. A large coefficient may produce faster adjustment, but tends to destabilize the system by overshooting reactions.

Our model thus suggests that compelling requirements of convergence and stability are overlooked in much of the current literature on rules for monetary policy. Special attention should be paid to parameters $\gamma$ and $\delta$, because of the deviation-amplifying role that short-run expectations play in the WK model. To appreciate this, it should be noted that the stability region of Proposition 5 features two different regimes: monotonic convergence for $\gamma<\frac{\left(1-\sqrt{\rho^{\prime}}\right)^{2}}{\alpha^{\prime} \beta^{\prime}}$, and damped oscillations otherwise. Consider the following example, where $a=0.4$ and $\rho=0.3$ are taken as primitive (realistic) values, which generate $\alpha=0.17$ and $\beta=0.67$. Choosing $\gamma=1$ as benchmark value, we would have monotonic convergence, if $\delta=0$, whereas $\delta=0.7$ would generate damped oscillations ${ }^{26}$. As $\delta$ approaches 1 , the $\gamma$ upper bound approaches 0 and then becomes negative. That is to say, the system oscillates and becomes unstable even for small values of $\gamma$ (unless the sign of the rule is inverted, lowering the interest rate when inflation is low, and vice versa). The search for inbuilt oscillations engaged early mathematizers of Wicksellian and Keynesian ideas under the presumption that business cycle theory ought to be able to reproduce cycles endogenously. That requirement has been dropped with the advent of modern DSGE methodology, which contents itself with ad-hoc calibration of stochastic processes of exogenous shocks.

Finally, it should be noted that the Wicksellian rule is "robust" in the sense of Orphanides and Williams (2002). Our model shows that, contrary to standard formulations of Taylor rules in the NNS literature, stabilization through the Wicksellian rule does not require direct information about the natural rates of interest or output. This is essential, as the unavailability of such information is a key hypothesis in the Wicksell-Keynes triangle. Our results also accord well with a growing literature that questions the hypothesis of timely and precise information about the natural rates in the $\mathrm{NNS}^{27}$. Like the "difference rules" discussed by Orphanides and Williams (2006), the Wicksellian rule of equation (4.7) belongs to the class of adaptive rules that, using step-by-step adjustments in view of observable changes in the economy, may drive the latter back to intertemporal equilibrium.

\footnotetext{
${ }^{26}$ For $\delta=0$, the system starts oscillating for $\gamma>1.83$, becoming unstable for $\gamma>23.3$. For $\delta=0.7$, the system starts oscillating for $\gamma>0.23$ and becomes unstable for $\gamma>5.6$.

${ }^{27}$ See, e.g., Orphanides and Williams (2002; 2002), Primiceri (2006) and Tamborini (2008).
} 


\section{Conclusions}

Answering the question, what Wicksell and Keynes knew about macroeconomics that modern economists fail to consider, we may now say "a lot". Attempting to capture some of their central insights our model shows that the macroeconomics of saving-investment imbalances, which dominated business-cycle theory in the first half of the 20th century, is not just a collection of pre-scientific insights. Its essential ingredients are amenable to rigorous treatment according to modern standards, with minimal deviations from the standard perfect competition model. Essentially all that is required is that the natural rate of interest should be volatile, and that it should not be easily transmitted to the capital market. Recent history testifies that these two conditions are sufficiently common and recurrent as to make saving-investment imbalances worth of being brought back to the forefront.

Contrasting the NNS triangle of intertemporal optimization, imperfect competition and sticky prices with the WK model - defined by the triangle of intertemporal coordination, imperfect capital markets and wrong interest rates -, we have found that, even though the two structures can be made to look similar, they lead to strongly different conclusions about the dynamic properties of systems in which interest-rate gaps occur. We believe that our conclusions provide an interesting basis for extending the scope of analysis of business cycles and of the role of monetary policy. The two triangles may converge towards the view that interest-rate rules are a crucial means to ensure stability. Yet it is obvious that the design of such rules requires further exploration, once it is accepted that the central bank may be misinformed about the natural interest rate, and that the dynamic properties of processes with saving-investment imbalances differ from those of the DSGE models (see e.g. Tamborini, 2008).

A critical issue, highlighted by our WK model through the interaction of parameters $\delta$ and $\gamma$, is the distribution of "short-term" and "long-term" inflation expectations and its possible endogenous changes - an interaction that gives rise to rich and complex dynamic processes. Another issue to be addressed is the effect that saving-investment imbalances may have on the capital stock and, hence, the further evolution of the economy. Once the additional capital is in place (or once a part of the previously optimal capital stock is scrapped), the economy can actually produce more (or less), slowing down (pushing up) inflation - regardless of whether this was the result of a wrong interest-rate signal or not. This phenomenon, which can be roughly described as aggregate demand and aggregate supply "moving together" (Greenwald and Stiglitz, 1987), is only marginally touched upon in the NNS literature (e.g. in Wooford, 2003b, ch. 5). Further extensions of the WK model should involve a more explicit treatment of financial structures, asset prices and their relations to the concept of the natural rate of 
interest. Given the analytical restrictions of the NNS triangle in all these respects, the scope of modelling in the spirit of Wicksell and Keynes merits further exploration.

\section{References}

Aghion, P., Frydman, R., Stiglitz, J. E., Woodford, M., 2004. Information and Expectations in Modern Macroeconomic: in Honor of Edmund S. Phelps. Princeton University Press, Princeton.

Bernanke, B., Gertler, M., 1990. Financial Fragility and Economic Performance. Quarterly Journal of Economics 105, 87-114.

Blanchard, O., 1997. Comment on Goodfriend and King. NBER Macroeconomics Annual 12, 289-293.

Blanchard, O., 2000. What do we know about Macroeconomics that Fisher and Wicksell did not? Quarterly Journal of Economics 115, 1375-1409.

Blanchard, O., 2008. The State of Macroeconomics. NBER Working Paper 14259.

Blanchard, O., Kiyotaki, N., 1987. Monopolistic Competition and the Effect of Aggregate Demand. American Economic Review 77, 647-666.

Boianovsky, M., Trautwein, H. M., 2006. Wicksell after Woodford. Journal of History of Economic Thought 28 (2), 171-185.

Boianovsky, M., Trautwein, H. M., 2006a. Price Expectations, Capital Accumulation and Employment: Lindahl's Macroeconomics drom the 1920s to the 1950s. Cambridge Journal of Economics 30, 881-900.

Borio, C., Lowe, P., 2002. Asset Prices, Financial and Monetary Stability: Exploring the Nexus. Bank of International Settlements 114.

Casares, M., McCallum, B. T., 2000. An Optimizing IS-LM Framework With Endogenous Investment. NBER Working Paper 7908.

Cassel, G., 1918. Theoretische Sozialökonomie. C.F. Winter, Leipzig.

Cooper, R., 2004. Monopolistic Competition and Macroeconomics: Theory and Quantitative Implications. In: Brakman, S., Heijdra, B. J. (Eds.), The Monopolistic Competition Revolution in Retrospect. Cambridge University Press, Cambridge.

Dixit, A., Stiglitz, J. E., 1977. Monopolistic Competition and the Optimum Product Diversity. American Economic Review 67, 297-308. 
Greenwald, B. C., Stiglitz, J. E., 1987. Keynesian, New Keynesian and New Classical Economics. Oxford Economic Papers 39, 119-133.

Hayek, F. A., 1931. Prices and Production. P.S. King, London.

Howitt, P., 1992. Interest Rate Control and Nonconvergence to Rational Expectations. Journal of Political Economy 100, 776-800.

Keynes, J. M., 1930. A Treatise on Money. Vol. 1 - The Pure Theory of Money. MacMillan.

Keynes, J. M., 1936. The General Theory of Employment, Interest and Money. MacMillan, London.

Laidler, D. W., 2006. Woodford and Wicksell on Interest and Prices. The Place of the Pure Credit Economy in the Theory of Monetary Policy. Journal of History of Economic Thought 28, 151-60.

Leijonhufvud, A., 1981. The Wicksell Connection: Variation on a Theme. In: Information and Coordination. Essays in Macroeconomic Theory. Oxford University Press, New York.

Leijonhufvud, A., 2008. Keynes and the Crises. CEPR Policy Insight 23.

Lindahl, E. R., 1930. Penningpolitikens medel. Förlagsaktiebolaget, Malmö.

Lundberg, E., 1930. Om begreppet ekonomisk jämvikt. Ekonomisk Tidskrift $32,133-160$.

Lundberg, E., 1937. Studies in the Theory of Economic Expansion. P.S. King, London.

Mankiw, G. N., Reis, R., 2003. Sticky Information: A Model of Monetary Nonneutrality. In: Aghion, P., Frydman, R., Stiglitz, J. E., Woodford, M. (Eds.), Information and Expectations in Modern Macroeconomic: in Honor of Edmund S. Phelps. Princeton University Press, Princeton.

McCallum, B. T., 1986. Some Issues Concerning Interest Rate Pegging, Price Level Indeterminacy, and the Real Bills Doctrine. Journal of Monetary Economics 17, 135-160.

Modigliani, F., 1944. Liquidity Preference and the Theory of Interest Rate and Money. Econometrica 12, 45-88.

Myrdal, G., 1931. Om penningteoretisk jämvikt. En studie över den "normala räntan" i Wicksells penninglära. Ekonomisk Tidskrift 33, 191-302.

Orphanides, A., Williams, J. C., 2002. Robust Monetary Policy Rules with Unknown Natural Rates. Brookings Papers on Economic Activity 2, 63118. 
Orphanides, A., Williams, J. C., 2006. Inflation Targeting Under Imperfect Knowledge. CEPR Discussion Paper Series 5664.

Patinkin, D., 1989. Money, Interest, and Prices : An Integration of Monetary and Value Theory. Cambridge University Press, Mass.

Pigou, A. C., 1933. The Theory of Unemployment. MacMillan, London.

Primiceri, G., 2006. Why Inflation Rose and Fell: Policy-Makers Beliefs and U.S. Postwar Stabilization Policy. Quarterly Journal of Economics 121, 867-901.

Sims, C., 2003. Implications of Rational Inattention. Journal of Monetary Economics 50, 665-690.

Tamborini, R., 2006. Back to Wicksell? In search of the foundations of practical monetary policy. Working Paper, Università degli Studi di Trento.

Tamborini, R., 2008. Monetary Policy with Investment-Saving Imbalances. Working Paper, Università degli Studi di Trento.

Wicksell, K., 1898. Geldzins und Gueterpreise. Eine Untersuchung uber die den Tauschwert des Geldes bestimmenden Ursachen. Gustav Fischer, Jena.

Wicksell, K., 1898a. The Influence of the Rate of Interest on Commodity Prices. In: Lindhal, E. R. (Ed.), Wicksell: Selected Papers in Economic Theory. Allen and Unwin, London.

Wicksell, K., 1901. Föreläsningar i Nationalekonomi, I: Teoretisk Nationalekonomi. Berlingska Boktryckeriet, Lund.

Wicksell, K., 1915. Föreläsningar i Nationalekonomi, II: Om Penningar och Kredit, 2nd Edition. Fritzes Hofbokhandel, Stockholm.

Wicksell, K., 1922. Vorlesungen über Nationalökonomie, Band 2: Geld und Kredit. Gustav Fischer, Jena.

Woodford, M., 1999. Revolution and Evolution in Twentieth-Century Macroeconomics. In: Gifford, P. (Ed.), Froniters of the Mind in the Twenty-First Century. Harvard University Press.

Woodford, M., 2003a. Imperfect Common Knowledge and the Effects of Monetary Policy. In: Aghion, P., Frydman, R., Stiglitz, J. E., Woodford, M. (Eds.), Information and Expectations in Modern Macroeconomic: in Honor of Edmund S. Phelps. Princeton University Press, Princeton.

Woodford, M., 2003b. Interest and Prices. Foundation of a theory of Monetary Policy. Princeton University Press. 
Woodford, M., 2006. Comment on Symposium on Interest and Prices. Journal of History of Economic Thought 28, 186-198.

\section{A Appendix}

\section{A.1 Interest rate gaps and output gaps}

Based on the model (3.1)-(3.8) in the text, we examine the allocations that result if, starting in the steady state, the market real interest rate at time $t, R_{t+1}$, differs from the natural rate $R^{*}$. Both rates are assumed to remain constant thereafter.

To begin with, recall that the steady state is characterized by $L^{*}=$ 1 (fully employed labour force), $\pi_{t+1}^{e}=\pi_{t}^{e}=\pi^{*}$ (constant expected or "normal" inflation rate), $\Theta=R^{*}$ (households' time discount factor equal to the gross real return to capital, or natural rate of interest), $C^{*}$ (constant consumption), $B^{*}=K^{*}$ (constant real stock of bonds representative of capital stock), $Y^{*}=H^{*}+R^{*} K^{*}$ (households' real income, given by labour, $H^{*}$, and capital, $R^{*} K^{*}$, incomes). Note that, as a consequence, $S_{t}^{\prime}=I_{t}^{\prime}=$ $K^{*}$, and once account is taken of capital replacement, net investment and saving are equal and nil.

Turning now to a period $t$ in which, cet. par., $R_{t+1} \neq R^{*}$, let us first examine households' optimal consumption path (see equation (3.8)):

$$
C_{t}=E_{t}\left[\frac{C_{t+1}}{R_{t+1}} R^{*}\right]
$$

Hence, with respect to the steady state, $R_{t+1} \neq R^{*}$ shifts consumption to the present (if $R_{t+1}<R^{*}$ ) or to the future (if $R_{t+1}>R^{*}$ ). Parallelly, households demand less or more (real) bonds, respectively.

Now let us see optimal investment of firms. This is (see equation (3.5)):

$$
I_{t}^{\prime}=K_{t+1}=\left(\frac{a}{R_{t+1}}\right)^{\frac{1}{1-a}}
$$

Hence, for $R_{t+1} \neq R^{*}$ investment is larger (if $R_{t+1}<R^{*}$ ) or smaller (if $R_{t+1}>R^{*}$ ). Firms supply more (real) bonds in the forme case, less in the latter.

As long as the central bank pegs $R_{t+1} \neq R^{*}$, it should stand ready to clear the excees supply of bonds (if $R_{t+1}<R^{*}$ ) or the excess demand of bonds (if $R_{t+1}>R^{*}$ ), allowing households and firms to finance their respective consumption and investment plans. However, these plans are not mutually consistent in the goods market. In fact,

- if $R_{t+1}>R^{*}$, consumption is shifted from $t$ to $t+1$, while investment in $t$, and the capital stock available in $t+1$, are reduced. There is excess supply in $t$ and excess demand in $t+1$, 
- if $R_{t+1}<R^{*}$, the excesses are reversed.

How can these inconsistent plans be transformed into mutually consistent demand and supply of output? To address this point, we follow the same procedure as in the NNS model, plugging the budget constraint period by period(see equation (3.7)) into households' Euler equation:

$$
H_{t}+R^{*} K^{*}-B_{t+1}=E_{t}\left[\frac{H_{t+1}+R_{t+1} B_{t+1}-B_{t+2}}{R_{t+1}} R^{*}\right]
$$

The saving-investment inconsistency leads to $B_{t+s} \neq K_{t+s}$ for $s=1, \ldots$, where the real value of the stock of bonds purchased by households differs from the actual stock of capital goods purchased by firms at each point in time. This results in wrong resource accounting. As long as $R_{t+1} \neq R^{*}$, the actual consumption path consistent with $B_{t+s}=K_{t+s}$ should satisfy:

$$
\left(Y_{t}-K_{t+1}\right)=\left(\frac{Y_{t+1}-K_{t+2}}{R_{t+1}} R^{*}\right)
$$

where $Y_{t}=H_{t}+R^{*} K^{*}$ and $Y_{t+1}=H_{t+1}+R_{t+1} K_{t+1}$. This reformulation of households' consumption path leads to the following propositions:

1. Given the capital stock chosen by firms for $R_{t+1} \neq R^{*}$, there exists a unique intertemporal vector of output realizations associated with consistent ex-post output market clearing.

2. These output realizations correspond to non-zero gaps with respect to the level of "potential output" given by the capital stock that would obtain with the natural rate of interest $R^{*}$.

The proof goes as follows. First, for $R_{t+1}$ constant, $K_{t+2}=K_{t+1}$. Hence, (A.4) can be rewritten as:

$$
Y_{t}=\frac{Y_{t+1}}{R_{t+1}} R^{*}+K_{t+1}\left(1-\frac{R^{*}}{R_{t+1}}\right)
$$

Now divide both sides by $Y^{*}$ we will obtain the intertemporal relationship between output gaps:

$$
\frac{Y_{t}}{Y^{*}}=\frac{Y_{t+1}}{Y^{*}} \frac{R^{*}}{R_{t+1}}+\frac{K_{t+1}}{Y^{*}}\left(1-\frac{R^{*}}{R_{t+1}}\right)
$$

Upon recollecting the following relationships:

$$
Y_{t+1}=K_{t+1}^{a}, Y^{*}=K^{a *}, K_{t+1}=\left(\frac{a}{R_{t+1}}\right)^{\frac{1}{1-a}}, K^{*}=\left(\frac{a}{R^{*}}\right)^{\frac{1}{1-a}}
$$

the two output gaps result:

$$
\hat{Y}_{t+1}=\left(\frac{R^{*}}{R_{t+1}}\right)^{\frac{a}{1-a}}
$$




$$
\hat{Y}_{t} \approx\left(\frac{R^{*}}{R_{t+1}}\right)^{\frac{1}{1-a}}
$$

where the approximation concerns the multiplicative term $\left[1-a\left(\frac{1}{R_{t+1}}-\frac{1}{R^{*}}\right)\right]$ which, for sufficiently small rates, is close to 1. (A.5) and (A.6) show that the main implication of the market real interest rate being set above (below) the natural rate is a sequence of negative (positive) output gaps each depending on the current interest-rate gap $\frac{R^{*}}{R_{t+1}}$.

\section{A.2 Inflation gaps}

As to price determination in relation to output gaps, given the generalequilibrium real wage rate $w^{*}$ and capital stock $K^{*}$ (see equation (3.5)), potential output at any time $t$ can also be expressed as:

$$
Y^{*}=K^{* a}\left(\frac{1-a}{w^{*}}\right)^{\frac{1-a}{a}}
$$

Since the nominal wage rate for $t$ be given by $W_{t}=w^{*} P_{t-1}\left(1+\pi^{*}\right)$, firms can adjust output for $t$ by choosing the labour input upon observing the current real wage rate $w_{t}=\frac{W_{t}}{P_{t}}$. As a result,

$$
Y_{t}=K^{* a}\left(\frac{1-a}{w^{*}} \frac{1+\pi_{t}}{1+\pi^{*}}\right)^{\frac{1-a}{a}}
$$

Ceteris paribus, profit-maximizing firms are ready to expand (contract) output as long as $\pi_{t}$, being greater (smaller) than $\pi^{*}$, increases (reduces) the current nominal value of the marginal product of labour vis-á-vis $W_{t}$. Conversely, we can derive the Marshallian supply curve of firms, that is, the inflation gap $\hat{\Pi}_{t} \equiv \frac{1+\pi_{t}}{1+\pi^{*}}$ which supports a given output gap. Let me divide (A.8) with (A.7):

$$
\hat{\Pi}_{t}=\hat{Y}_{t}^{\frac{a}{1-a}}
$$

